\title{
Sociodemographic Profile of Road Traffic Accident Victims admitted at Emergency Surgical OPD of a Tertiary Care Hospital
}

\author{
Amita Aggarwal, Sukhpal Kaur, Mandeep S Dhillon
}

\begin{abstract}
Objective: To assess sociodemographic profile of roadside accident victims.
\end{abstract}

Materials and methods: Using purposive sampling technique 100 patients were enrolled in the study. A questionnaire consisting of personal identification data, personal habits and details related to occurrence of accident was used to collect the data.

Results: More than half subjects (59\%) were in age group of 20 to 40 years with mean age being 36.5 years \pm 14 .2. Majority of the accident victims (84\%) were male. More than half (67\%) belonged to Hindu religion, educated up to secondary level $(65 \%)$, were married (54\%) and were rural habitants (54\%). Twenty-six percent of subjects had the history of drinking alcohol. Out of these 15 subjects (57.7\%) had consumed alcohol at the time of accident. Sixty-eight percent were driving two wheeler; only $27 \%$ were wearing protective equipment (helmet/seat belt) at the time of accident. Approximately onethird (39\%) had 6 to 15 years of driving experience. Half (51\%) of the accidents occurred in evening hours and on Saturday and Sunday.

Conclusion: The present study reflects that there is need to plan strategies to decrease risk of accidents and inculcate healthy driving habits in the vulnerable citizens.

Keywords: Sociodemographic profile, Road traffic accident victims.

How to cite this article: Aggarwal A, Kaur S, Dhillon MS. Sociodemographic Profile of Road Traffic Accident Victims Admitted at Emergency Surgical OPD of a Tertiary Care Hospital. J Postgrad Med Edu Res 2012;46(1):15-18.

Source of support: Nil

Conflict of interest: None declared

\section{INTRODUCTION}

The main cause of injuries can be attributed to man's ever increasing desire to move faster than his two legs can carry him. This attitude reflects his mind and quest for inventing faster and stronger machines as means of communication and transportation. Such machines have brought along with them an increase in the number of road traffic accidents (RTAs), both in air and on the road. This increase has been noted in various countries worldwide and India also has a significant contribution to the increasing number. It is expected that by year 2020 accidents will rank third in the global burden of diseases. ${ }^{1}$
Road traffic accident injuries account for $2.1 \%$ of global mortality; $85 \%$ of all RTA deaths occur in developing countries and nearly half are in the Asia-Pacific region. ${ }^{2}$ Continuous growth in the number of vehicles, poor enforcement of traffic safety rules and regulations, inadequacy of health infrastructure, and poor access to health care are some of the important reasons for the high burden of road traffic injuries in the developing countries. ${ }^{3}$

Accidents tragically are not often due to ignorance but are due to carelessness, thoughtlessness and over confidence. Indian road data shows that $83.5 \%$ of accidents were due to driver's fault, but other contributing factors were mechanical defects in vehicles (3\%), pedestrian fault (2.3\%), fault of passenger (2.4\%), bad roads (1.1\%), bad weather $(0.9 \%)$ and other factors like cattle, fallen trees on the roads (6\%), etc. ${ }^{4}$

The number and occurrence of RTA is directly influenced by sociodemographic profile of road users. Pedestrians, bicyclists and motorized two wheelers have been identified as most vulnerable group constituting 60 to $80 \%$ of road fatalities in India. ${ }^{5}$ Although India has just $1 \%$ of the total vehicles in the world but it contributes to $6 \%$ of global RTAs. ${ }^{6}$ Data from India and other developed countries has shown that factors like human errors, alcohol use, ignorance of rules, large number and often overloaded buses, defective roads, poor street lighting, defective layout of cross roads and speed breakers, etc. were significant contributors to road accidents. In an attempt to evaluate and confirm the above facts and compile data regarding the sociodemographic profile of RTA we under took the prospective study. It is felt that these facts may help policy makers to evolve programs aimed at prevention of roadside accidents. The present study was conducted on RTA victims brought to the tertiary care hospital.

\section{MATERIALS AND METHODS}

The study was conducted in emergency surgical OPD, PGIMER, Chandigarh. All the patients suffering from trauma and surgical illnesses requiring emergency care are admitted here. Purposive sampling technique was adopted 
and 100 roadside accident victims were taken up for the study. Each victim (if conscious) was interviewed using an interview schedule. Otherwise caregivers were asked regarding the occurrence of accident. The questions asked were related to personal identification, personal habits and details related to occurrence of accidents. The validity of the tool was established.

\section{RESULTS}

\section{Demographic Profile of the Subjects}

Fifty-nine percent of the RTA victims were in age group of 20 to 40 years with mean age being 36.5 years \pm 14.2 (range 03 years to 60 years). Majority (84\%) were male and more than half $(67 \%)$ belonged to Hindu religion. Sixty-five percent were educated upto secondary level. Fifty-four percent each were married and were rural habitants. Twentyone percent were working in private sector, $18 \%$ were students and equal number were unskilled workers. A total of $63 \%$ RTA victims had 1 to 4 family members and around half (49\%) had ₹ 1001 to 2000/ per capita income per month. (Table 1).

\section{Personal Habits of the Subjects}

On reviewing the personal habits, we noted that 26 and $13 \%$ subjects had the history of alcohol and tobacco consumption respectively. Twenty-six percent used to take alcohol occasionally. A total of 15 out of 26 (57.7\%) had accident under the influence of liquor (Table 2).

\section{Details related to Occurrence of Accidents}

Sixty-eight percent of the victims were driving at the time of accident. Only $27 \%$ were wearing protective equipment (helmet and seat belt). A total of 39\% had 6 to 15 years of driving experience. Among all 6\% had met with an accident in the past. As per day and time of accident, more than half of accidents had occurred on Saturday and Sunday and in evening hours (Table 3).

\section{DISCUSSION}

Present study was conducted to assess sociodemographic profile of roadside accident victims. More than half (59\%) of RTA victims were in the prime of their productive lives (20 to 40 years), leading to a double loss to the society, first by loosing the productive man-days and second by spending money on treatment. Subsequent life long disability and crippling consequences of the RTAs may add to the burden on the nation. The higher incidence of RTAs in this young
Table 1: Sociodemographic profile of the subjects $(N=100)$

\begin{tabular}{cll}
\hline Personal identification & $N$ \\
\hline 1. Age (in years) & Mean age \pm SD 36.5 years \pm 14.2 & \\
- $0-20$ & Range $=3$ to 60 years & 17 \\
- $20-40$ & & 59 \\
- $40-60$ & & 21 \\
& $60-80$ & 03
\end{tabular}

2. Gender

- Male 84

- Female 16

3. Religion

- Hindu 67

- Muslim 05

- Sikhism 27

- Buddhism 01

4. Educational status

- Illiterate 13

- Primary 13

- Middle 17

- Secondary 22

- Senior secondary 18

- Graduate 14

- Postgraduate/professional degree 03

5. Marital status

- Married 54

- Unmarried 40

- Widow/Widower 06

6. Habitat

- Rural 54

- Urban 46

7. Occupation

- Student 18

- Government service 05

- Private sector 21

- Self employed - Business 14

- Agriculture 03

- Skilled workers 09

- Unskilled workers 18

- Not working/house wife 12

8. Total family income (₹)

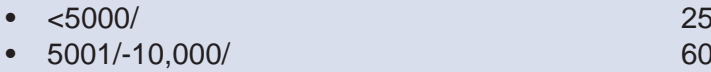

- $10001 /-15,000 / 213$

- 15001/-20,000/ 02

9. Total family members

$\begin{array}{ll}\text { - } 1-4 & 63 \\ \text { - 5-8 } & 33\end{array}$

- 9-12 04

10. Per capita income $(₹)$

- $<1000 / 1001 /-2000 / \quad 30$

- $1001 /-2000 / 2001 /-3000 / 249$

- 3001/-4000/ 05

and important age group has also been reported in the other studies. ${ }^{7-9}$ Higher number of males as RTA victims in the current study can be attributed to the fact that normally in our society females lead a comparatively less active life and mostly remain indoor. Similar results were also noted by other researchers. ${ }^{9,10}$

Majority of the subjects (83\%) were undergraduate and had family income less than Rs 10,000/month (85\%). Jha ${ }^{11}$ 
Table 2: Personal habits of the subjects $(N=100)$

\begin{tabular}{lr}
\hline Personal habits & $N(\%)$ \\
\hline 1. Type of habit & \\
- Alcohol & 26 \\
- Tobacco & 13 \\
2. Frequency of alcohol consumption & $\mathrm{N}=26$ \\
- Daily & $02(07.7)$ \\
- Twice a week & $03(11.5)$ \\
- Weekly & $07(26.9)$ \\
• Occasionally & $14(53.9)$ \\
3. Amount of daily alcohol & $\mathrm{N}=26$ \\
- One peg & $02(07.7)$ \\
- Two-three pegs & $20(76.9)$ \\
- More than 3 pegs & $04(15.4)$ \\
4. Intake of alcohol at time of accident & \\
- Yes & $15 / 26(57.7 \%)$ \\
\hline
\end{tabular}

Table 3: Details related to occurrence of accidents $(N=100)$

\begin{tabular}{|c|c|c|}
\hline \multicolumn{2}{|c|}{ Variables } & \multirow[t]{2}{*}{$N$} \\
\hline 1. & At time of accident subject was & \\
\hline & - Driver & 68 \\
\hline & - Pillion/passenger & 24 \\
\hline & - Pedestrian & 08 \\
\hline \multirow{5}{*}{2.} & Type of vehicle & \\
\hline & - Two wheeler & 68 \\
\hline & - Three wheeler & 10 \\
\hline & - Four wheeler & 17 \\
\hline & - Bicycle & 05 \\
\hline \multirow[t]{4}{*}{3.} & $\begin{array}{l}\text { Use of protective equipment at } \\
\text { time of accident }\end{array}$ & \\
\hline & - Yes & 27 \\
\hline & - No & 60 \\
\hline & - Not applicable & 13 \\
\hline \multirow[t]{6}{*}{4.} & Experience of driving (years) & \\
\hline & - $1-5$ & 22 \\
\hline & - $6-15$ & 39 \\
\hline & - $16-25$ & 06 \\
\hline & - $36-45$ & 01 \\
\hline & - Not applicable & 32 \\
\hline \multirow[t]{3}{*}{5.} & Accident in past & \\
\hline & - Yes & 06 \\
\hline & - No & 94 \\
\hline \multirow[t]{3}{*}{6.} & Number of accidents in past $(\mathrm{N}=6)$ & \\
\hline & - Once & 05 (83.3) \\
\hline & - Twice & $01(16.7)$ \\
\hline \multirow[t]{4}{*}{7.} & Time of accident & \\
\hline & - Morning & 21 \\
\hline & - Evening & 51 \\
\hline & - Night & 28 \\
\hline \multirow[t]{8}{*}{8.} & Day of accident & \\
\hline & - Monday & 14 \\
\hline & - Tuesday & 11 \\
\hline & - Wednesday & 06 \\
\hline & - Thursday & 08 \\
\hline & - Friday & 10 \\
\hline & - Saturday & 30 \\
\hline & - Sunday & 21 \\
\hline
\end{tabular}

and $\mathrm{Mohan}^{5}$ have reported the similar findings in their studies. More than half of the subjects (57.7\%) out of those who used to drink, had consumed alcohol at time of accident, though majority was aware of the fact that driving under the influence of alcohol is not permitted by the law. Consumption of alcohol increases the probability of accident as it impairs the judgment and reflexes resulting in slowing of thinking and response. As per the results of one study around $30 \%$ of the victims were under the influence of alcohol at the time of accident. ${ }^{11}$

Though in most parts of the country, two wheeler (male) and four wheeler drivers are suppose to wear helmets and seat belts respectively; however, only $27 \%$ were wearing these safety gadgets in the current study. Sixty-eight percent of the victims were driving two wheeler at the time of accident. Occupants of the two wheelers constitute to the majority to be affected in the road traffic injuries. ${ }^{12}$ More than half of accidents occurred on Saturday and Sundays and in evening hours (3-8 pm). In the weekends many people enjoy their leisure time, go out of their homes and expose themselves to the accidents, 3 to $8 \mathrm{pm}$ timing is the time for getting the schools and the offices off and for the people to go back to their homes. There is more traffic rush during these hours. A study conducted at JIPMER, Puducherry reported that the highest number of accidents took place on Sunday (17.1\%) and peak time for roadside accident was in the evening hours (18.2\%), the occupants of various vehicles constituted 45\% of victims, two wheeler drivers were more (31.1\%) involved in accidents. ${ }^{11}$

In the light of above-discussed issues, it is emphasized that there is a need to plan and implement more strategic interventions with regard to traffic rules in order to decrease the burden of disability and death due to road traffic accidents. It is recommended to carry out further studies on the evaluation of subjects' awareness of benefits of using seat belts/helmets and dangers of driving under the influence of alcohol.

\section{REFERENCES}

1. Murray C, Lopez A. The global burden of disease. Cambridge MA: Harvard University Press 1996;1.

2. http://www.newsindia-times.com/2002/09/13/med30-poor.html. Accessed on 25 July 2009.

3. Nantulya MV, Reich MR. The neglected epidemic: Road traffic injuries in developing countries. BMJ 2002;324: 1139-41.

4. Drive and Safety Alive, inc. Roads deaths in India, 2000-2002. Available from: http://www.driveandstayalive.com.

5. Dinesh M. The raod ahead, traffic injuries and fatalities in India. TRIPP transportation research and injury prevention programme, WHO Collaboration centre.

6. Madan VS. Road traffic accidents: Emerging epidemic. Indian Journal of Neurotrauma 2006;3:1-3. 
7. Ghos PK. Epidemiological study of the victims of vehicular accidents in Delhi. J Indian Med Assoc 1992;90:309-12.

8. Balogun JA, Abereoje OK. Pattern of road traffic accident cases in a Nigerian University teaching hospital between 1987-1990. J Trop Med and Hygiene 1992;95:23-29.

9. Ganveer GB, Tiwari RR. Injury pattern among nonfatal road traffic accident cases: A cross-sectional study in central India. Indian J Med Sci 2005;59:9-12.

10. Frank TM. The effectiveness of bicyclists helmet: A study of 1710 casualities. J Trauma 1993;34:834-45.

11. Jha N, Srinivasa DK, Roy G, Jagdish S. Epidemiological study of road traffic accident cases: A study from South India. Indian J Comm Med 2004;24:20-24.

12. Patil SS, Kakade RV, Durgawale PM, Kakade SV. Pattern of road traffic injuries: A study from Western Maharashtra. Indian J Comm Med 2008;33:56-57.

\section{ABOUT THE AUTHORS}

\section{Amita Aggarwal}

Nursing Intern, National Institute of Nursing Education, Postgraduate Institute of Medical Education and Research, Chandigarh, India

\section{Sukhpal Kaur (Corresponding Author)}

Lecturer, National Institute of Nursing Education, Postgraduate Institute of Medical Education and Research, Chandigarh, India e-mail: sukhpal.trehan@yahoo.in

\section{Mandeep S Dhillon}

Professor and Head, Department of Orthopedics, Postgraduate Institute of Medical Education and Research, Chandigarh, India 